\title{
Transforming Industrial Complexes to Innovative Clusters? A Korean Case Study
}

\author{
Sang-Chul Park \\ Sang-Chul Park, Korea Polytechnic University, Graduate School of Knowledge based Technology and \\ Energy, Korea (scpark@kpu.ac.kr) / Korea Advanced Institute of Science and Technology, Korea \\ (scpark86@kaist.ac.kr)
}

\begin{abstract}
Global economic environment based on globalization processes caused a severe competition between the nations, and these nations launched various strategic approaches to increase their market shares in the global markets. The economic globalization process stimulates changes of technology environment that is not favor for the technology advanced nations to transfer their strategic technology areas toward developing and newly industrialized nations. Moreover, due to the change of external economic and technological environment national development strategies in all nations are also changing. In order to generate economic growth and gain a better position in severe competition between nations, the advanced nations have already established strong national and regional innovation systems The nations participating in the globalization processes actively tend to close free trade agreements (FTA) in order to intensify the movement of their production factors across the national borders as quick as possible. This new trend has cognized the importance of regions and regional competitiveness that are based on regional industries. In line with the new trend of global economies, building innovative local clusters has become one of the core strategies to develop the nations further. This frame shift has affected South Korea to a high extent because the nation cannot develop further without inventing its own core technology that costs a vast capital as well as takes a long time. This paper examines an attempt to restructure existing industrial complexes, turning them into innovative clusters at regional and local level. This contribution also tries to identify the tasks and strategies necessary to build locally embedded innovative clusters and how to best analyze these.
\end{abstract}

Keywords: innovative cluster, transition, globalization, low-tech, high-tech, economic growth

\section{Introduction}

Global economic environment based on globalization processes has been changed since the cold war era was finished in the end of the 1980s. Since then, comparative competitiveness between the nations is regarded as economic power instead of political and military power. Such an external economic change caused a severe competition between the nations, and these nations launched various strategic approaches to increase their market shares in the global markets. This is described as an economic globalization process (Dicken 2007). The economic globalization process stimulates changes of technology environment that is not favour for the technology advanced nations to transfer their strategic technology areas toward developing and newly industrialized nations. This frame shift has affected South Korea to a high extent because the nation cannot develop further without inventing its own core technology that costs a vast capital as well as takes a long time. With the economic globalization process the concept of national boarder may have been falling since capital, technology, and highly educated manpower are footless. This new trend has cognized the importance of regions and regional competitiveness that are based on regional 
industries. In line with the new trend of global economies, building innovative regional clusters has become one of the core strategies to develop the nations further (OECD 1999).

Banwol \& Siwha National Industrial Complex has been regarded as a global supply base for components and materials industries that are composed of nearly 10,000 SMEs. In fact, the complex is the largest industrial site in the world in terms of the total number of SMEs concentrated in the one spot. Despite the agglomerated locational advantage, the complex has had a visible limitation on mainly production oriented functions that could result in lessening competitiveness in the long run. Arguing that it is imperative to actively react to the process of economic globalization, this paper examines an attempt to restructure existing industrial complexes, turning them into innovative clusters at regional and local level. This contribution also tries to identify the tasks and strategies necessary to build locally embedded innovative clusters and how to best analyze these.

\section{Theoretical Considerations}

Malecki (1991) described that technology is a key element in regional growth, and hightech firms are both dynamic and offer high-quality and high-wage jobs for workers. For this reason, most nations use a combination of national and regional policies to stimulate innovation. Additionally, Oakey and Mukhtar (1999) explained that national policies include technical education, government support for R\&D, technology transfer and protection for strategic industrial sectors, while regional policies focus on stimulating measures for innovation such as investment, grants, science parks and technopoles. Porter (2000) stressed that innovative clusters represent a new way of thinking about national, state, and local economies. These create new roles for companies, government, and other institutions in enhancing competitiveness. This paper is based on the path creation theory and focuses on whether this theory can be adopted for the South Korean approach to restructure the existing industrial complexes to the innovative clusters or not.

Regarding the accumulation of technical knowledge, Dosi (1982) already urged that the knowledge leads to the formation of a path of possible technical developments. Furthermore, the cumulative nature of the technological process narrows down the range of potential choices that is regarded as the evolution of the technology proceeds. David (1985) characterized this as the path dependency theory embodying strong prescriptions about which technological change should be pursued and which should be neglected. Where the cumulative nature of the process of technological development involves the narrowing of ranges of potential choices, national trajectories enable differentiation and diversification from the main development path (OECD 1992). However, Schienstock and Hämäläinen (2001) argued that a risk of path dependency exists when a specific development path in an economy exhausts itself. This is indicated by a loss of competitiveness, retarding economic growth, and increasing unemployment. Therefore, Grabher (1993) and Schienstock (1997) insisted that such a lock-in phenomenon suggests paying more attention to the aspect of path creation.

As such, a theory of path creation can provide a way of understanding how entrepreneurs escape a lock-in situation. Garud and Karnoe (2000) explained that path creation is interpreted as a process of transforming a technological field in which different actors with different frames are cooperating. In the transformation process, the entrepreneur plays a main role as a stimulator and coordinator at a business level. 
According to the path-creation perspective, all economic actors are regarded as knowledgeable agents with a capacity to react in ways other than those prescribed by the existing social rules and technological artefacts. However, David (2000) argued that a new path-creating innovation needs the development and coordination of a vast array of complementary elements that include new management techniques, new organization forms, new kind of workforce skills, new infrastructure, government policies, public organizations etc. Path creation processes require the importance of trial and error. Stable processes of path creation and diffusion can generate positive results if all actors of an innovation system cooperate, review each other's change processes and finally adapt to them. In addition, continuous exchange of information and knowledge in dialogues and multi-logues is required for stabilizing a new development path. In this regard, Schienstock (2007) explained that the government plays a key role in the path creation process. Furthermore, path creation also needs new forms of coordinating and various innovation activities such as vision creation and discursive coordination.

\section{A Korean Case Study}

\section{Background and Local Environment}

Banwol \& Siwha National Industrial Complex (B\&S NIC) is one of 35 national industrial complexes. It was planned to be established in the end of the 1970s by the central government. The government started to build the industrial complex in 1977 and completed in 2004. It is located in the two cities such as Ansan City and Siheung City, Gyeonggi-Province that is a part of Seoul Metropolitan areas.

B\&S NIC is a large sized area. It is a ca. $32 \mathrm{~km}^{2}$ complex, and industrial area is about $19 \mathrm{~km}^{2}$. The area is based on land reclamation. By creating the area, many questions about environmental effects had been raised. However, the then military regime continued the construction in the 1980s. The main reason for it was that the then government tried to move out environmental pollution producing companies located in Guro Industrial Complex in Seoul due to heavy pollution and strong resistance of residents living nearby (KICOX 2007).

The companies moved to B\&S NIC were mainly engaged in low-tech industrial sectors such as chemical and steal related industries. These companies had strong linkages with large sized companies in a verticalized subcontracting relationship. Therefore, they needed to be localized near to the large sized companies. B\&S NIC became the largest SMEs concentrated industrial area. In 2008, there were 3,752 companies and 6,948 companies in Banwol and Siwha respectively. In total, 10,700 companies were operating in the complex (KICOX 2007).

Around the complex two major universities and three technical colleges are located. These universities and colleges support SMEs operating in the complex. Major tasks of academia and industry focus on close collaboration between the two actors in order to develop new products as well as technology transfers. Moreover, three national research institutes are also located in the complex. These institutes support and cooperate with academia and industry.

\section{Industrial Structure and Characteristic}

B\&S NIC is the largest SMEs agglomerated area in Korea, in which components for machine, electronics and automobile, fine chemicals and new materials for textiles are co-existed. Among various industrial sectors in the complex, three major industrial sectors such as machine, electrics \& electronics and petrochemicals accounted for about 
70.8 per cent of the total number of companies operating in the complex in 2007. In these major industrial sectors, the largest share was machine that accounts for about 45 per cent. Electrics \& electronics and petrochemicals followed with the shares of 15 per cent and 10 per cent respectively.

Among the operating companies, the number of the large sized company is 35 that hire over 300 employees. The rest, ca. 9,750 is small and medium sized companies. It means that over 99.7 per cent of the companies are SMEs. Among these, companies hiring employees less than 50 are the absolutely majority. The total number of companies located in the complex accounted for about 22 per cent of the companies in the Gyounggi Province in 2007. The total output of the complex reached ca. 45 trillion won (ca. 45 billion US dollars) in 2007 that also accounted for about 22 per cent of the total output in the Gyounggi Province. In addition, the total number of employees was 171,592 that were about 20 per cent of the province (Korea National Statistical Office 2008, Gyounggi Province 2008).

In the complex, the most of operating companies are involved in components and materials. The total number of components and materials related companies reached 4,886 in 2008 that accounted for 44.2 per cent. Among these, the components companies accounted for 81.6 per cent, while the materials companies were 18.2 per cent. The former consists of machine components, electrics and electronics and IT. The latter are composed of nano, fine chemicals, textile and metal (Banwol \& Siwha Cluster Agency 2009).

Industrial characteristics are based on the following four factors that indicate structural strength and weakness of B\&S NIC as well as companies characters operating in the complex. First: mainly subcontractor for large sized companies. Over 89 per cent of the companies located in the complex is SMEs operating with less than 50 employees. 76 per cent of these companies have its revenue less than two billion won. As a result, the most of companies are not able to carry out R\&D activity and to access to the global market by themselves. Second: production cost down as a major strategy. Due to the weak R\&D capability, the most of SMEs set the target to reduce their production cost as much as possible in order to compete with other SMEs. All conglomerates also demand strongly their subcontractor to minimize their production costs in order to compete with other global companies. Therefore, SMEs are forced to concentrate on reducing production costs based on cost saving management instead of technology and management innovation. Third: strict industrial regulation in the metropolitan area and worsening business environment. The complex is located in the metropolitan area, which is strictly regulated by the law restraining excessive development. Therefore, companies starting their new business need to receive various permissions and follow strict environmental regulations. As a result, most of new starting companies prefer to operate as tenants of the rental companies that result in small business structurally. Fourth: mainly components and material sectors. By developing in various industrial sectors, components and materials industries have been growing rapidly. Thus, the complex has become the area of largest concentrated components and materials industries (KICOX 2007).

\section{Performance of B\&S NIC}

B\&S NIC has developed continuously since its establishment. Particularly it has created an outstanding performance in terms of number of company, revenue and employment. In the year 1980 only 309 companies were located, and its total revenue reached 59 
billion won. In the complex, only 8,700 employees worked at that time. Around three decades later, the total number of companies increased up to 9,784 and its total output grew about 800 times that accounted for 45 trillion won. Furthermore, the total number of employees also increased dramatically from 8,700 to 171,592.

As a result, it may be safe to say that the complex has expanded successfully and played its role properly to operate as a nation's major product base. In each decade the complex exposes its clear characteristics. In the 1980s revenue and employment increased rapidly, while the total number of companies and revenue expanded dramatically in the 1990s. Since the year 2000 all three sectors have outperformed in balance. (Table 1)

Table 1: Growth Pattern of Banwol \& Siwha NIC, 1980-2007

\begin{tabular}{l|llll}
\hline & $\mathbf{1 9 8 0}$ & $\mathbf{1 9 9 0}$ & $\mathbf{2 0 0 0}$ & $\mathbf{2 0 0 7}$ \\
\hline No. of company & 309 & 1,096 & 4,209 & 9,784 \\
Output (Billion won*) & 59 & 4,644 & 24,988 & 45,044 \\
No. of employment & 8,700 & 9,500 & 11,295 & 171,592 \\
\hline
\end{tabular}

Note: * 1 billion won is approximately 1 million US dollars

Source: KICOX, Statistical Data $(2007,2008)$

\section{Transformation Strategies}

The cluster policy is one of the main policies for the balanced national development. For realizing the policy, the government nominated seven national industrial complexes and one national science and technology special zone as model innovative clusters. The former is Banwol \& Siwha in Seoul metropolitan area, Gunsan in Mid-west, Kwangju in South-west, Changwon in South, Gumi in South-east, Ulsan in South-east, and Wonju in East. The latter is Daedeok Innopolis located in Daejeon. These model clusters are representative national industrial complexes and science and technology site in Korea. Their output accounted for ca. 50 per cent of the national industrial output in 2007. In addition, these model clusters are located evenly in nationwide that take the balanced national development into consideration (www.kicox.or.kr 2008-03-14).

These eight model clusters focuses on their strategic industrial areas that contributes to strengthening their competitiveness and generating regional economic growth. At the same time, these are committed to create their own local innovation system for cooperating with academia located in the local areas. The model clusters are cooperating and competing under control of Korea Industrial Complex Corporation (KICOX) that is a public company created by the Ministry of Knowledge and Economy. Among the eight model clusters B\&S NIC is chosen to be explored how to transform towards an innovative cluster. The cluster represents components and materials industry of Korea.

The national industrial complex is a large sized industrial site, while the regional industrial complex is small and medium sized. It is true that industrial complexes contributed to a rapid economic growth in a short period particularly from 1960s to the mid 1990s. During this period, Korean industrial complexes were very effective and competitive for generating mass production. However, the complexes faced difficulties due to a high labour cost and low priced Chinese products on global markets since the 2000s. In fact, the most of Korean national industrial complexes have been insufficient to create a sustainable development based on technology innovation and highly value added products because their major function has been based on production technologies instead of generating technology innovation backed by R\&D activities. In order to 
overcome difficulties, the government started to carry out a cluster policy in 2004 that focuses on technology innovation as well as regional economic growth.

It is not an easy task to transform B\&S NIC to an innovative cluster. The major problem is that the most of the companies located in the complex has mainly focused on production activity without any R\&D activity in spite of a high number of companies. Simply these companies have not been able to invest their resources into the $R \& D$ activity due to its physical limitation.

Under the circumstances, Banwol \& Siwha Cluster Agency (BSCA) started to implement the cluster policy in the complex since the year 2004. Owing to an inferior innovative environment based on a large number of SMEs functioning mostly as first and second layer of subcontractor, BSCA possessed little room to create any framework for building an innovative cluster. Additionally, BSCA did not have any experience of management in the complex, but it had delivered administrative services regarding locating companies in the complex until 2004.

The cluster policy was launched by the former government in line with the national balanced policy in 2004. In order to implement the national balanced policy, KICOX was committed to transform the seven existing national industrial complexes to innovative clusters. BSCA as a regional headquarter of KICOX has been in charge of transforming processes.

By launching the plan for transformation, the task of BSCA has been changed to act actively as a major innovative actor creating innovative environment and developing management skills. For it, BSCA has created a taskforce team for transforming an innovative cluster and hired several well educated employees as a specialized group.

The strategies for transforming an innovative cluster that BSCA has carried out are as follows:

First: building mini clusters. To build mini clusters is a common strategy of KICOX to transform the national industrial clusters chosen as model clusters into innovative clusters. A mini cluster means that over 30 companies operating in the same or similar business areas in the complex build a small sized regular meeting group in order to create a close network that enables to exchange information about market, technology, labour, financing etc.

BSCA had built 13 mini clusters until 2007 because there were over 9,000 companies as well as over ten industrial sectors. The total number of mini clusters reduced to eight in 2008. The reason for it is that the taskforce team to build mini clusters could not cover the high number of mini clusters properly due to its limited man power. Additionally, it may be wise for them to choose a certain kind of companies to become members of the mini clusters in order to create a successful model (KICOX 2007).

In the mini clusters company and university play major roles in collaborating for their common interests. Furthermore, research institute and supporting organization also participate in the mini clusters. BSCA created eight mini clusters in three industrial sectors such as components, materials and infrastructure technology in 2008. In total 802 members participated in the mini cluster activities in the same year.

In the beginning of the mini cluster activity, the performance was rather poor than expected due to low credibility of BSCA. The most of located companies used to regard BSCA as a control institute instead of as support organization. In order to overcome this kind of prejudice, BSCA tried to find out joint projects participated by companies, universities and research institutes as well as to discuss how to solve 
problems and difficulties that companies faced. Additionally, BSCA hold technology related forums and seminars that all innovative actors were interested in. As a result, BSCA created 1,067 networking activities between members, and 13,484 peoples participated until 2007 (KICOX 2007).

Second, creating a global supply base for high value added components and materials B\&S NIC has over ten industrial sectors. By nature, it is not focused and specialized. Various industrial sectors co-exist. A common characteristic is SMEs based that are mostly subcontractors for conglomerates located in the metropolitan area. Therefore, BSCA intensifies its strategic view in creating the complex as a supply base for high value added core components and materials. The reason for it is that companies in the complex mark lower productivity and value added compared to the national average (Table 2). The former accounted for about 77 per cent while the latter reached only 74 per cent in 2007.

Table 2: Comparison of Productivity and Value Added in Selected Industries

\begin{tabular}{l|lccc}
\hline \multirow{2}{*}{ Sector } & \multicolumn{2}{|c}{ Nation } & \multicolumn{2}{c}{ Banwol \& Siwha } \\
\cline { 2 - 5 } & Manufacturing & $\begin{array}{l}\text { Components \& } \\
\text { Materials } \\
\text { - Million won - }\end{array}$ & $\begin{array}{c}\text { Manufacturing } \\
\text { Materials }\end{array}$ \\
\hline $\begin{array}{l}\text { Amount of } \\
\text { product/ person } \\
\begin{array}{l}\text { Value added/ } \\
\text { person }\end{array}\end{array}$ & 220 & 220 & 193 & - Million won - \\
\hline
\end{tabular}

Source: KICOX, Customized Development Strategy in National Industrial Complex (2007)

Third, collaboration between industry and university. As explained, the complex has been a core production base for components and materials industries in the metropolitan area. Over 99 per cent of the companies in the complex is SMEs and possesses little R\&D capability. This result in lower productivity and value added compared to the national average. Over 70 per cent of the companies in the complex do not operate any R\&D centre. Furthermore, about 26 per cent of the companies do not invest any resource into R\&D activity, and 49.4 per cent of the companies invest less than five per cent of their revenue.

In order to overcome this chronic problem, BSCA has tried to build a strong collaboration between industry and university located in the same area. However, most of collaboration between these actors uses to be based on joint projects that do not focus on basic and apply technology development, but developmental technology as well as technology advices regardless their sizes.

As a result, the activity of collaboration in the area exposes a limitation to create technological innovation for strengthening competitiveness of the complex as well as to generate sustainable regional economic growth. Despite the structural limitation, BSCA tries to intensify collaboration between two actors continuously due to its gradual improvement to upgrade technological capability of the companies and to solve difficulties that the most of the companies faces in the complex.

\section{A Successful Transformation?}

BSCA has conducted transformation processes of B\&S NIC into an innovative cluster since 2004. The reason for the necessity of the transformation is based on a structural disadvantage of industrial complex owing to production oriented capability without 
R\&D activity. Therefore, BSCA is keen to transform the complex into an innovative cluster that can increase productivity and value added products based on R\&D activity.

In order to analyze the transformation processes 802 members of the mini clusters were targeted to ask whether activities of BSCA could impact on their business properly or not. For it, a survey was conducted by BSCA in 2007 that was focused on pattern of R\&D activity, networking between industry, university and research institute, and number of domestic patent application etc. that are important factors for becoming an innovative cluster (BSCA 2008).

In the pattern of R\&D activity, the most of member companies preferred to carry out their R\&D activity by themselves, while the joint R\&D activity between company and university accounted only for 8.1 per cent. Surprisingly enough, companies collaborated with other companies more than with universities. It may indicate that the cooperative relationship between the two actors was not based on mutual trust yet (Table 3).

The current situation of building networks between companies and universities also shows that universities and research institutes could not contribute to creating close networks for the companies properly. Only less than 20 per cent of the total companies agreed that university and research institute provided some support to build networks they need. Moreover, the companies regarded a close network with university as unnecessary owing to their verticalized relationship with large sized companies (Table 4).

Table 3: Pattern of Companies’ R\&D Activity - Banwol \& Siwha NIC

\begin{tabular}{lllll}
\hline Independent & Cooperative \& Commission based & & Others \\
\hline & $\begin{array}{l}\text { Commission based } \\
\text { with University \& } \\
\text { Research Institute }\end{array}$ & $\begin{array}{l}\text { Cooperation with } \\
\text { University \& } \\
\text { Research Institute }\end{array}$ & $\begin{array}{l}\text { Cooperation with other } \\
\text { companies }\end{array}$ & \\
\hline $47.5 \%$ & $1.0 \%$ & $8.1 \%$ & $20.2 \%$ & $23.2 \%$ \\
\hline \multicolumn{2}{l}{ Source: Banwol \& Siwha Cluster Agency (2008) }
\end{tabular}

Table 4: Current Situation of Company Networks - Banwol \& Siwha NIC

\begin{tabular}{l|llllll} 
Sector & $\begin{array}{l}\text { Very } \\
\text { supportive }\end{array}$ & Supportive & $\begin{array}{l}\text { Little } \\
\text { supportive }\end{array}$ & No support & $\begin{array}{l}\text { No } \\
\text { relation }\end{array}$ & Total \\
\hline $\begin{array}{l}\text { University } \\
\begin{array}{l}\text { Research } \\
\text { Institute }\end{array}\end{array}$ & $4.0 \%$ & $12.1 \%$ & $23.2 \%$ & $6.1 \%$ & $54.5 \%$ & $100 \%$ \\
\hline
\end{tabular}

Source: Banwol \& Siwha Cluster Agency (2008)

Finally, BSCA has supported a few companies participating in joint projects with universities and research institute since 2004. As a result, the participated companies created technological development with the support of universities and research institutes. The number of domestic patent application reached only six in 2005. However, this number grew continuously year by year. In 2008, the number increased up to 60. The highest number of domestic patent application reached 80 in 2007. Unfortunately, there was no international patent application. A year later, this number decreased 25 per cent due to global economic slowdown.

In sum, the transformation process does not seem to be very positive. Particularly building network and collaboration between companies and universities may not be in a proper track that is needed to develop continuously. At the same time, however, the number of domestic patent application based on joint projects between 
companies and universities has increased from 2005 to 2007 rapidly although this trend was down turned in 2008.

BSCA tried to build a platform in which all innovative actors such as private companies, universities and research institutes and local governments strongly interact one another for maximizing their mutual interests. However, BSCA as a part of central government organization was not able to cooperate with local governments due to the regulations that do not allow local governments participating in the designated national industrial complex. Therefore, BSCA is only able to implement its strategies focusing on collaboration with companies, universities and research institutes that resulted in weak cooperation. As a result, the path creation theory based on strong interaction between innovative actors may be difficult to be applied in the context of B\&S NIC.

\section{Conclusions}

It is absolutely true that national and regional industrial complexes have contributed to a rapid economic growth and a successful industrialization in Korea. In particular, 35 national industrial complexes have played major roles in the industrialization processes last four decades. As a result, the 35 complexes produced about 40 per cent of GDP and exported about 48 per cent of the total exports in 2007. Moreover, the national complexes hired about 20 per cent of employees in the same year.

B\&S NIC as one of the major national complexes has also played a core role in terms of output, export and employment in the Gyeonggi Province located in the Seoul Metropolitan area. However, its limitation as one of the national production bases started to be visible with the globalization process.

Therefore, the former government launched the cluster policy in order to transform eight model clusters into innovative clusters in 2004. The concept of an innovative cluster is based on a strong interaction between innovative actors such as industry, universities and government. Furthermore, technology innovation and sustainable economic growth must be taken place continuously in a concentrated area. It means that the result of R\&D activity must be engaged in commercialized new products as soon as possible within the area.

In order to transform B\&S NIC to an innovative cluster, BSCA created a taskforce team dealing with cooperation and interaction between industry and universities in 2004. BSCA has focused on three strategic targets that are building mini cluster, creating a global supply base for high value added components and materials, and collaboration between industry and universities.

These targets are not easy tasks for BSCA to realize in short time with a limited manpower specialized in clustering assignment ordered by KICOX. Regarding the survey carried out by BSCA, a high number of member companies in the mini clusters complained about weak performance and incredibility in the first and second years. After the year 2006 the transformation process became better than previous years. The number of domestic patent application can prove this positive trend in the year 2006 and 2007.

However, the global economic crisis in 2008 hit the Korean national economy, particularly in the national industrial complexes because the complexes used to be heavily dependent on exports. Furthermore, the new government, which commenced in February 2008, does not have any strong intention to follow the policies launched by the former government as planned. Therefore, BSCA has struggled for vitalizing the 
transformation process continuously since 2008. It seems to be that the complex still has a long way to go for realizing an innovative cluster.

\section{References}

Banwol and Siwha Cluster Agency (BSCA) 2008. Internal Report. Ansan: BSCA.

Banwol and Siwha Cluster Agency (BSCA) 2009. Implementation Measures for Structural Upgrading in Banwol \& Siwha Industrial Complex. Ansan: BSCA.

David, P. 1985. Clio and the economics of QWERTY. Economic History, 75, 227-323.

David, P. 2000. Understanding digital technology's evolution and the path of measured productivity growth: Present and future in the mirror of the past, in Understanding the Digital Economy, edited by E. Brynolfsson and B. Kahin. Boston: MIT Press.

Dicken, P. 2007. Global Shift. London: Sage.

Dosi, G. 1982. Technological paradigms and technological trajectories: A suggested interpretation of the determinants and directions of technological change. Research Policy, 11, 147-162.

Garud, R. and Karnoe, P. 2000. Path Creation as a Process of Mindful Deviation. Paper to the conference on knowledge and innovation, Helsinki, 25-26 May 2000.

Grabher, G. 1993. The weakness of strong ties: The lock-in of regional development in the Ruhr Area, in The Embedded Firm: On the Socio-Economics of Industrial Networks, edited by G. Grabher. London: Routledge.

Gyounggi Province 2008. Industrial Production Statistics. Suwon: GP.

Korea Industrial Complex Corporation (KICOX) 2007. Customized Development Strategy in National Industrial Complex. Seoul: KICOX.

Korea National Statistical Office 2008. Statistics on Manufacturing. Seoul: KNSO.

Malecki, E.J. 1991. Technology and Economic Development. Harlow: Longman.

Oakey, R.P. and Mukhtar, S.M. 1999. United Kingdom small firms in theory and practice: A review of recent trends. International Small Business Journal, 17, 48-64.

OECD 1992. Technology and the Economy: The Key Relationships. Paris: OECD.

OECD 1999. Boosting Innovation: The Cluster Approach. Paris: OECD.

Porter, M.E. 2000. Location, competition and economic development: Local clusters in a global economy. Economic Development Quarterly, 14(1), 15-34.

Schienstock, G. 1997. The Transformation of regional governance: Institutional lock-ins and the development of lean production in Baden-Württemberg, in Governance at Work: The Social Regulation of Economic Relations in Europe, edited by R. Whitley and P.H. Kristensen. Oxford: Oxford University Press.

Schienstock, G. 2007. From path dependency to path creation: Finland on its way to the knowledge-based economy. Current Sociology, 55(1), 92-109.

Schienstock, G. and Hämäläinen, T. 2001. Transformation of the Finnish Innovation System: A Network Approach. SITRA Reports Series 7. Available online at: http://www.kicox.or.kr [accessed: 11 June 2010]. 